\title{
Universal Mail Ballot Delivery Boosts Turnout: The Causal Effects of Sending Mail Ballots to All Registered Voters
}

\author{
R. Michael Alvarez and Yimeng Li* \\ California Institute of Technology
}

December 15, 2021

\begin{abstract}
Some American states have transitioned to universal voting-by-mail, where all registered voters receive a ballot in the mail. While this practice was growing in popularity prior to the 2020 general election, universal voting-by-mail was suddenly used in a larger number of states due to the COVID-19 pandemic. In this paper, we utilize a unique situation in which registered voters in some legislative districts in Los Angeles County were subjected to universal voting-by-mail in the March 2020 primary, while most of the rest of the Los Angeles County electorate was not. Using differencein-difference and regression discontinuity designs, we take advantage of this unique within-jurisdiction situation to estimate the causal effects of universal voting-by-mail on voter turnout and on who votes. Our results indicate that voter turnout increased by around $3 \%$ for voters who do not automatically receive a ballot in the mail otherwise, and the increase is larger for registered partisan voters than those without a party affiliation.
\end{abstract}

${ }^{*}$ This research was presented at the 38th Annual Meeting of the Society for Political Methodology (Polmeth 2021). We thank John Marshall for his comments. This work was also presented at the 5th Annual Election Sciences, Reform, and Administration Conference (ESRA 2021), and we thank conference participants for their feedback. We thank Jian Cao for his help with some of the data used in this paper. We also thank the California Secretary of State, the Los Angeles County Registrar-Registrar/County Clerk, and the Orange County Registrar of Voters, for their help with data and for answering our many questions about election administration. 


\section{Introduction}

Research on voting by mail in the United States has concentrated on two questions. First, does offering eligible voters the opportunity to obtain and return their ballot by mail increase the likelihood that they will cast a ballot? Past research has disagreed on the answer, as some find that voting by mail may increase voter turnout modestly (Southwell and Burchett, 2000; Richey, 2008; Gerber, Huber and Hill, 2013; Keele and Titiunik, 2018), with others arguing that voting by mail does not boost turnout (Gronke and Miller, 2012; Kousser and Mullin, 2007).

The second question focuses on whether offering a voting-by-mail option changes who votes, and whether it changes the demographic or political composition of the electorate. Most early studies found that making registration and voting more convenient did not have strong partisan consequences (Wolfinger and Rosenstone, 1980; Patterson and Caldeira, 1985), which has been confirmed in more recent research (Gerber, Huber and Hill, 2013; Thompson et al., 2020; Barber and Holbein, 2020; Bonica et al., 2021).

In our study we estimate the causal effects of this method of voting within a single jurisdiction. We use data from Los Angeles County's March 2, 2020 primary election, conducted before the COVID-19 pandemic altered California election administration), where voters in some legislative districts received ballots in the mail while voters in neighboring areas of the county did not.

Our within-jurisdiction design mitigates potential confounding factors that exist in earlier cross-county and cross-state studies. Counties in California are the basic unit of election jurisdiction, and in terms of the administration of the 2020 primary election, there was little other than universal voting by 
mail that varied across the districts in our analysis. And while Los Angeles County has considerable demographic diversity, we take that into consideration in our analyses discussed below. In particular, recognizing that registered voters are not uniformly distributed throughout Los Angeles County, we account for heterogeneity by estimating the treatment effects in specific legislative districts within the county. Thus our study has strong internal validity, in particular relative to previous studies employing cross-county or cross-state variation.

In addition to leveraging within-county variation, our design has two other advantages. First, we distinguish between permanent and non-permanent absentee voters and separately estimate the effects of the universal vote-by-mail on these two groups of voters. Since permanent absentee voters automatically receive a mail ballot regardless of the policy, estimating the effects on registered voters as a whole conflates how many voters are affected by the policy. Secondly, our study is the first to use a regression discontinuity design to estimate the effects of universal vote-by-mail on voter turnout. By focusing on the local average treatment effect of the policy, the regression discontinuity design accounts for unobservable confounders that may remain in the difference-in-difference design.

\section{Data and Methods}

Section 4007 of the California's Voter's Choice Act (VCA) required Los Angeles County to send mail ballots to voters who live in state legislative or federal congressional districts that span Los Angeles and other neighboring VCA counties. ${ }^{1}$

\footnotetext{
${ }^{1}$ California Elections Code, Division 4, Mail Ballot Elections, Section 4007(a)(8) https://leginfo.legislature.ca.gov/faces/codes_displayText.xhtml?lawCode=ELEC\&division=4 . \&title $=\&$ part $=\&$ chapter $=1 . \&$ article $=$.
} 
Since Orange County is the only VCA county adjacent to Los Angeles County in the 2020 election cycle, voters residing in districts spanning Los Angeles County and Orange County automatically received a mail ballot for the March 2020 presidential primary elections, regardless of their permanent absentee status. We call these districts universal vote-by-mail districts. Figure SI.1 in the Supplementary Materials displays a congressional district map in Los Angeles County showing the universal and non-universal vote-by-mail districts.

We use voter files from Los Angeles County for the June 2018 statewide primary elections and the March 2020 presidential primary elections. The voter files contain each registered voter's name, address, permanent absentee status, registration precinct, whether they voted in the 2018 and 2020 primary elections, and whether they voted by mail or in person.

Our analysis proceeds in three stages. We start by using a difference-indifference design to estimate the effects of sending mail ballots to all registered voters, on turnout and the composition of the electorate, for voters in all districts in Los Angeles County (stage one), and then for only voters in California's 32nd and 40th congressional districts (stage two). The focus on those two congressional districts helps us avoid potential confounding factors that might exist across congressional districts.

Specifically in our difference-in-difference analyses we compare voters residing in universal vote-by-mail districts (the treatment group) to those living in non-universal vote-by-mail districts (the control group), in terms of their turnout in 2020 (after the policy was implemented) relative to 2018 (before the policy was implemented). Crucially, we conduct the difference-in-difference analysis for non-permanent absentee voters and permanent absentee voters separately. ${ }^{2}$

\footnotetext{
${ }^{2}$ We include in the category permanent absentee all registered voters designated as being
} 
For non-permanent absentee voters, mail ballots were automatically sent to them only if they reside in universal vote-by-mail districts and only in 2020 . Therefore the difference in difference in turnout yields an estimate of the desired causal effect. By contrast, since permanent absentee voters receive mail ballots automatically regardless of the policy under consideration, the policy should not directly affect them but may have spillover effects. In the Supplemental Materials Section SI.3 we test the parallel trends assumption.

In the third stage, we estimate the causal effects of sending mail ballots to all registered voters using a regression discontinuity design. The regression discontinuity design allows us to estimate the local average treatment effect of the policy on voters residing near the boundary of universal and non-universal voteby-mail districts. To do so, we first geo-locate all registered voters residing within 2 kilometers of the boundary using the Google Maps API. Then we calculate the distances of these registered voters' addresses to the boundary and conduct a regression discontinuity analysis using the distance to the boundary as the running variable. By focusing on the causal effects on voters residing close to the boundary, the regression discontinuity design provides us a way to control for remaining confounding factors in our difference-in-difference analysis. In the Supplemental Materials Section SI.4, we examine balance in voter demographics in universal and non-universal vote-by-mail district. Finally in the Supplemental Materials Section SI.6 we provide the approach proposed in Keele and Titiunik (2015) to explore the heterogeneous treatment effects along the boundary.

covered by the Uniformed and Overseas Citizens Absentee Voting Act (UOCAVA voters). UOCAVA voters account for less than $1 \%$ of permanent absentee voters. 


\section{Results}

\subsection{All Districts in Los Angeles County}

We begin by looking at the effects of sending mail ballots to all registered voters on the percent of voters voting by mail, separately for permanent absentee voters and non-permanent absentee voters (Figure 1, left panel). For permanent absentee voters, sending mail ballots to all registered voters does not directly impact them because they automatically receive a mail ballot for each election. We find that permanent absentee voters in universal vote-by-mail districts and non-universal vote-by-mail districts cast their vote by mail in substantively similar percentages in both the 2018 and 2020 elections. For non-permanent absentee voters, however, the policy has a direct impact on them because they automatically receive a mail ballot only if they reside in a universal vote-by-mail district. Those residing in a non-universal vote-by-mail district need to request a mail ballot before the request deadline to vote by mail. We see a drastic increase in the percentage of voters voting by mail (38\%) in universal vote-by-mail districts only, in 2020 compared to 2018 (details provided in Table SI.3).

We now look at the effects of sending mail ballots to all registered voters on voter turnout (Figure 1, right panel). ${ }^{3}$ We find that non-permanent absentee voters in universal vote-by-mail districts saw a much larger increase in turnout in 2020 compared to 2018 than those in non-universal vote-by-mail districts. The result indicates a $3.3 \%$ boost in turnout across Los Angeles County attributable

\footnotetext{
${ }^{3}$ Here we compare voter turnout for the same group of voters between 2018 and 2020 (the denominator for voter turnout is the total number of registered voters in 2020), the relevant comparison for the difference-in-difference analysis. Results are similar if we compare turnout between 2018 non-permanent absentee voters and 2020 non-permanent absentee voters (different groups of voters), using the number of registered voters in each year as the denominator respectively.
} 
Figure 1: Effects of Sending Mail Ballots to All Registered Voters on Percent of Voters Voting by Mail and Voter Turnout, All Districts in Los Angeles County

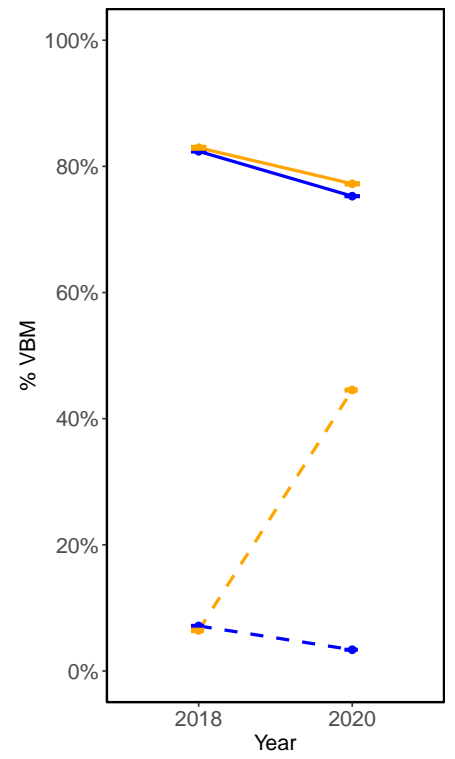

Universal VBM Districts $\rightarrow$ No $\rightarrow$ Ye: Permanent VBM Voters - No - Ye:

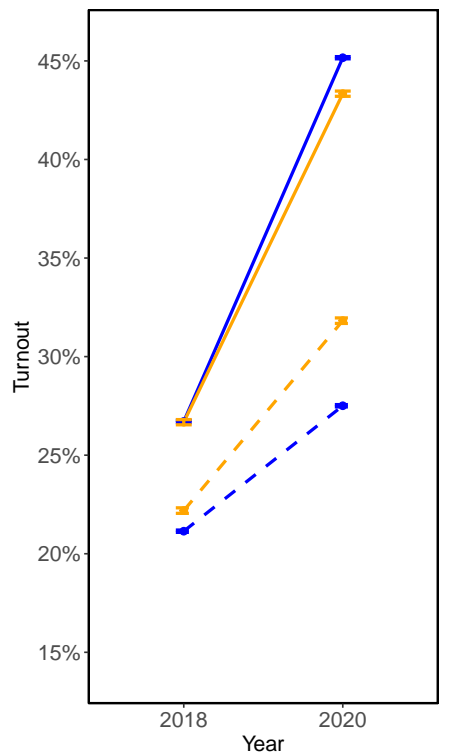

Universal VBM Districts $\rightarrow$ No $\rightarrow$ Yes Permanent VBM Voters - No - Yes

Note: In this figure and hereafter, Permanent VBM Voters are those who automatically receive a ballot in the mail for the 2020 primary elections regardless of the districts in which they live. Universal VBM Districts refer to congressional districts and state legislative districts where all registered voters automatically receive a ballot in the mail in the 2020 primary elections. The lines trace the turnout of the same group of voters in the previous primary election. The y-axes of the two panels are on different scales. Complete results are in Table SI.3.

to the policy, according to our difference-in-difference estimates. By contrast, among permanent absentee voters, the increase in turnout in 2020 compared to 2018 appears lower in universal vote-by-mail districts than non-universal vote-by-mail districts (details provided in Table SI.3).

Finally, we look at whether sending mail ballots to all registered voters has different effects on voters of different party registrations (Figure 2). First, permanent absentee Democratic voters and non-permanent absentee Democratic 
Figure 2: Effects of Sending Mail Ballots to All Registered Voters on Voter Turnout by Party Registration, All Districts in Los Angeles County

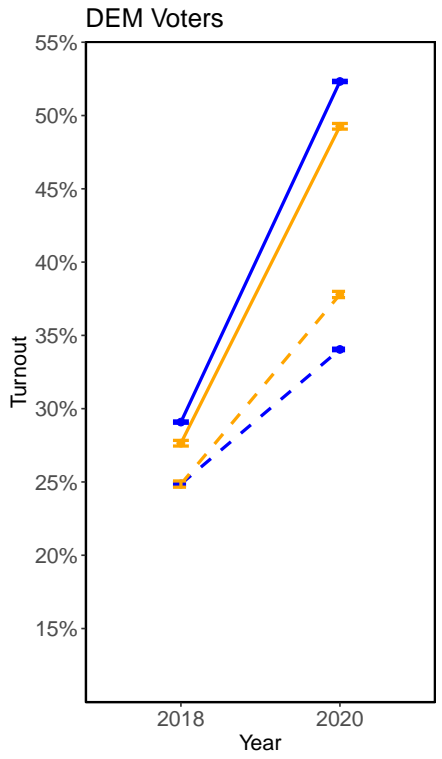

Universal VBM Districts $\rightarrow$ No $\rightarrow$ Yes Permanent VBM Voters - No - Yes

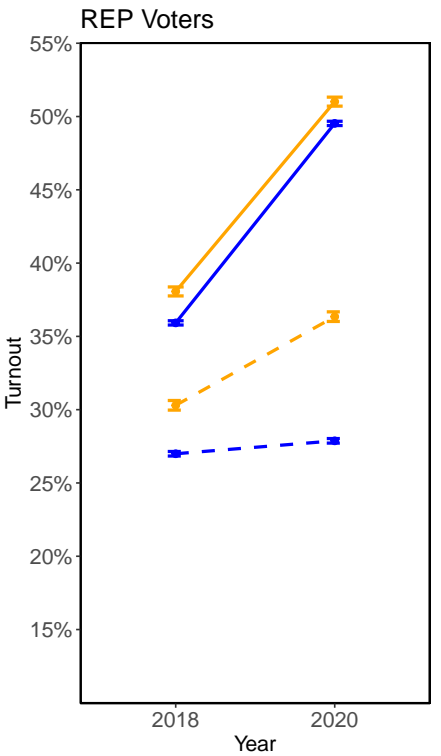

Universal VBM Districts $\rightarrow$ No $\rightarrow$ Yes Permanent VBM Voters - No - Yes

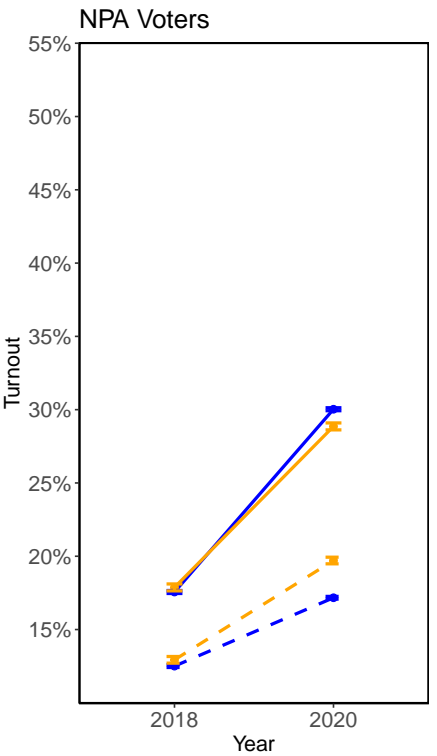

Universal VBM Districts $\rightarrow$ No $\rightarrow$ Yes Permanent VBM Voters - No - Yes

Note: Complete results are in Table SI.4.

voters in both types of districts saw a larger increase in turnout (in 2020 compared to 2018) than Republican voters and non-party-affiliated voters, which is expected given that there was a contested Democratic presidential primary election. ${ }^{4}$ However, the differential increase in turnout in universal vote-by-mail districts over non-universal vote-by-mail districts is larger for registered Republicans $(5.2 \%)$ than registered Democrats (3.8\%) and non-party-affiliated voters (2.1\%) (Table SI.4). These results indicate that turnout increased for registered voters in the universal vote-by-mail districts regardless of party registration, but that the increase in turnout was greater for registered partisan voters than those

\footnotetext{
${ }^{4}$ California traditionally holds statewide primary elections in June, but broke with that tradition by holding the 2020 primary election in March.
} 
without a party affiliation.

\subsection{California's 32nd and 40th Congressional Districts}

To further control for potential congressional district effects and leverage only within-county within-congressional-district variation, we look at voters residing in universal vote-by-mail districts and non-universal vote-by-mail districts in California's 32nd and 40th congressional districts. Figure SI.2 in the Supplementary Materials shows maps of these congressional districts. While these congressional districts are entirely within Los Angeles County, they contain state senate districts that span Los Angeles and Orange counties (29th state senate district for CA-32 and 32nd state senate district for CA-40). As a result, among voters residing in California's 32nd and 40th congressional districts, those living in these state senate districts automatically receive a mail ballot, while those living in other state senate districts only receive a mail ballot if they register as permanent absentee voters or request one.

The results from our analysis of California's 32nd congressional district are presented in Figure 3 (voter turnout) and Table SI.5 (percent of voters voting by mail). Similar to what we find in our analysis of the entire county, we see a drastic increase in the percentage of non-permanent absentee voters voting by mail (39\%) only in the 29 th state senate district, the universal vote-by-mail district. Next, while turnout for non-permanent absentee voters residing in both types of districts increased in 2020 compared to 2018, the increase is larger in the universal vote-by-mail district (the 29th state senate district, 9.2\%) than the non-universal vote-by-mail districts (other state senate districts, $7.2 \%$ ). The results indicate a $2 \%$ boost in turnout in California's $32 \mathrm{nd}$ congressional district 
Figure 3: Effects of Sending Mail Ballots to All Registered Voters on Voter Turnout, CA-32 (Left) and CA-40 (Right)

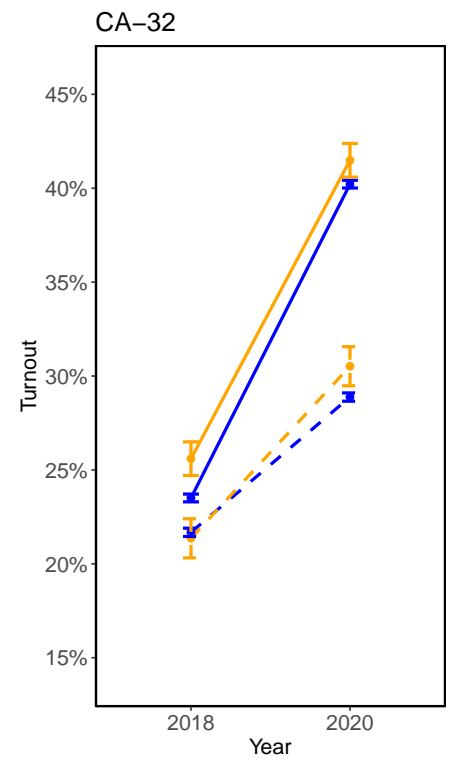

Universal VBM Districts $\rightarrow$ No $\approx$ Yes

Permanent VBM Voters - No - Yes

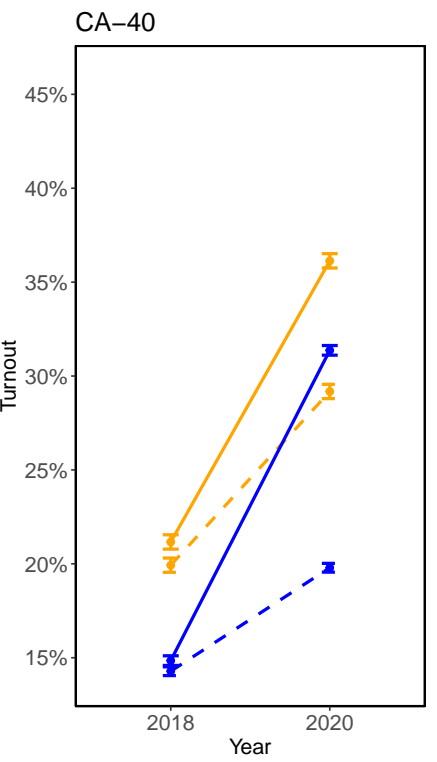

Universal VBM Districts $\rightarrow$ No $\rightarrow$ Yes

Permanent VBM Voters - No - Yes

Note: Complete results are in Table SI.5 (CA-32) and Table SI.6 (CA-40).

attributable to the policy, according to our difference-in-difference estimates (Table SI.5). By contrast, for permanent absentee voters in California's 32nd congressional district, the increase is smaller in the universal vote-by-mail district than the non-universal vote-by-mail districts.

The results from our analysis of California's 40th congressional district are presented in Figure 3 (voter turnout) and Table SI.6 (percent of voters voting by mail). Again, we see a drastic increase in the percentage of non-permanent absentee voters voting by mail (38\%) only in the universal vote-by-mail district. Moreover, while both types of districts see an increase in turnout in $2020 \mathrm{com}$ pared to 2018 , the increase is $9.2 \%$ for the universal vote-by-mail district (the 32nd state senate district), which is much greater than the $5.5 \%$ increase for the 
non-universal vote-by-mail districts (other state senate districts) (Table SI.6). The result indicates a 3.7\% boost in turnout in California's 40th congressional district attributable to the policy, according to our difference-in-difference estimates. The effect is unlikely due to other factors, given that the increase is smaller in the universal vote-by-mail district than the non-universal vote-by-mail districts for permanent absentee voters.

Finally, we look at the effects of sending mail ballots to all registered voters on voter turnout by party registration (Figure 4). For California's 32nd congressional district, the differential increase in turnout among non-permanent absentee voters in universal vote-by-mail districts over non-universal vote-by-mail districts is much larger for registered Republicans (4.6\%) than registered Democrats (1.8\%) and non-party-affiliated voters (1.2\%) (Table SI.7). For California's 40th congressional district, however, the differential increase among non-permanent absentee voters in turnout is larger for registered Democrats $(6.1 \%)$ than registered Republicans (3.1\%) and non-party-affiliated voters (Table SI.8). Therefore, the differential increase in turnout among non-permanent absentee voters in universal vote-by-mail districts over non-universal vote-by-mail districts is larger for registered partisan voters than those without a party affiliation, similar to what we found in the countywide analysis. The comparison between registered Democrats and Republicans, however, differs across different congressional districts within the county. 
Figure 4: Effects of Sending Mail Ballots to All Registered Voters on Voter Turnout by Party Registration, CA-32 (Top) and CA-40 (Bottom)
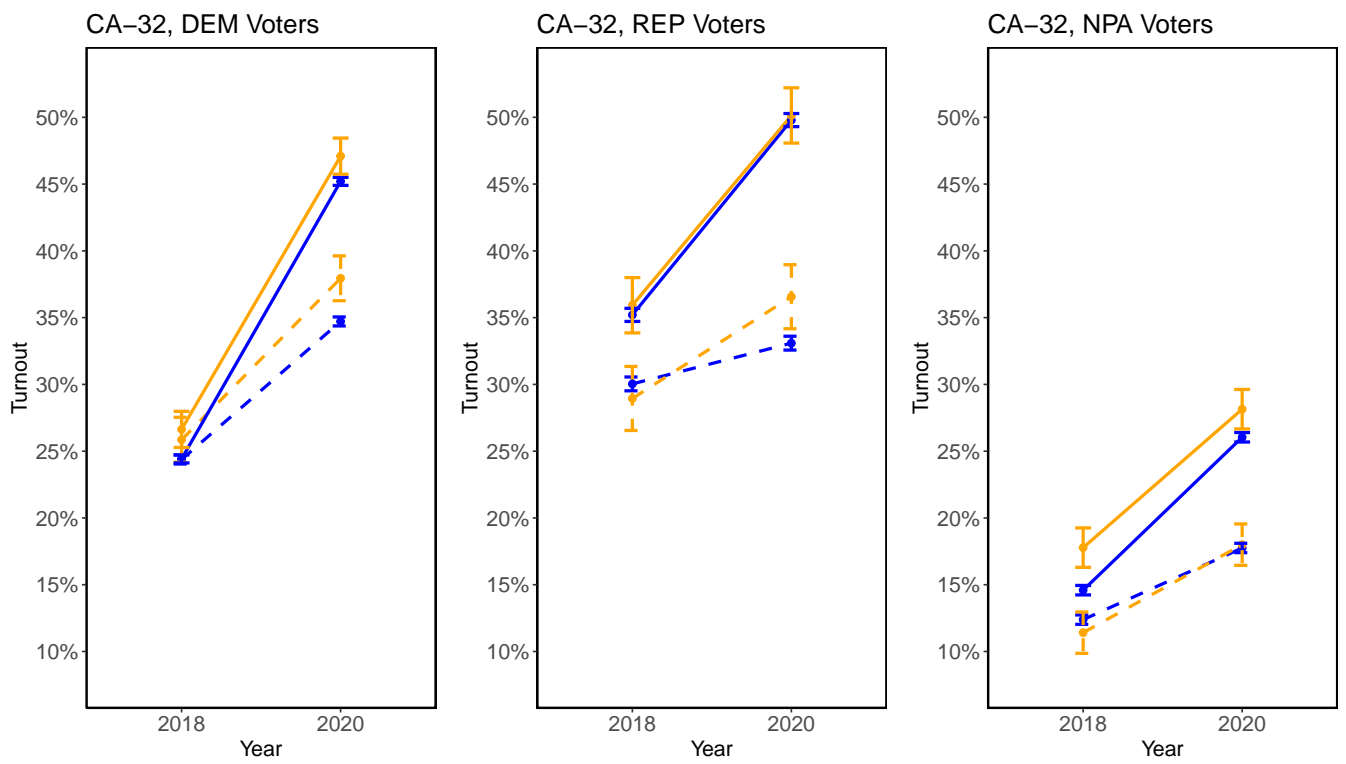

Universal VBM Districts $\rightarrow$ No $\rightarrow$ Yes

Universal VBM Districts $\rightarrow$ No $\rightarrow$ Yes

Universal VBM Districts $\rightarrow$ No $\rightarrow$ Yes

Permanent VBM Voters - No - Yes

Permanent VBM Voters - No - Yes

Permanent VBM Voters - No - Yes
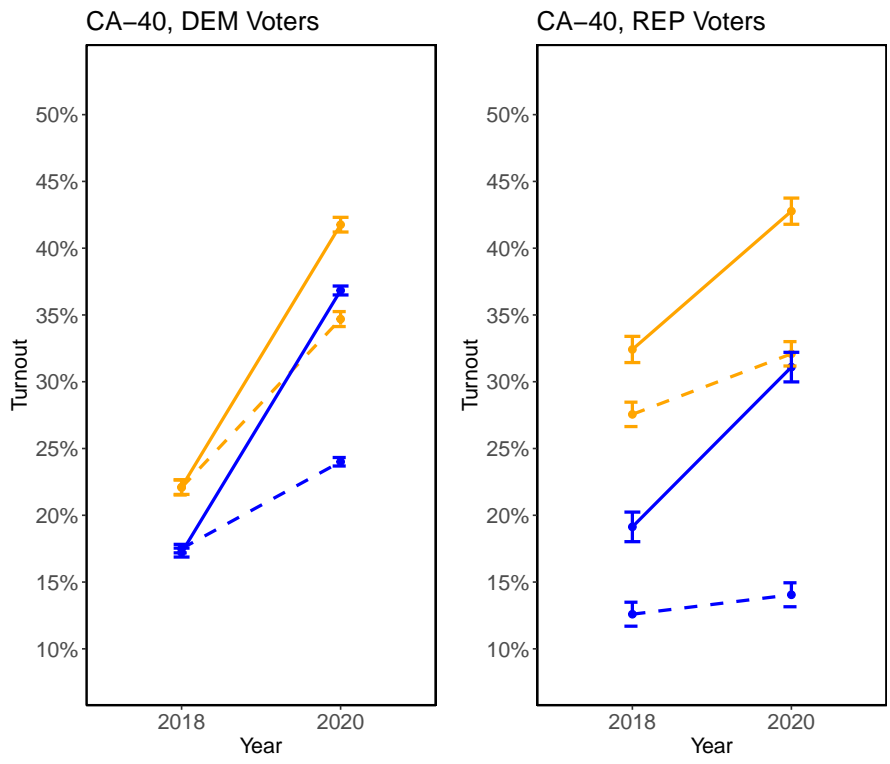

CA-40, NPA Voters

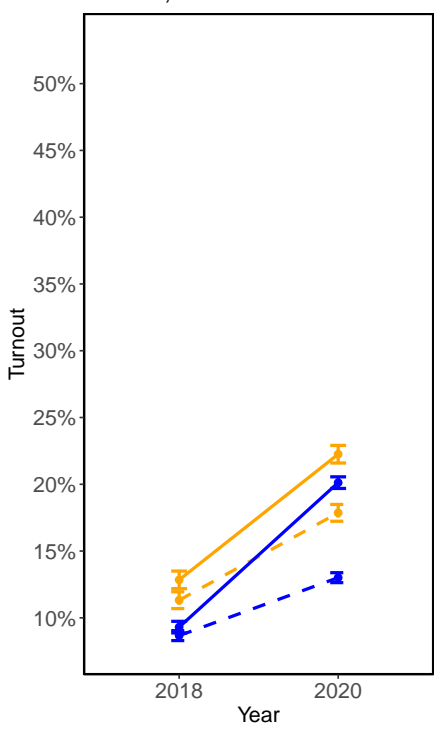

Universal VBM Districts $\rightarrow$ No $\Rightarrow$ Yes

Universal VBM Districts $\rightarrow$ No $=$ Yes

Universal VBM Districts $\rightarrow$ No $\rightleftharpoons$ Yes

Permanent VBM Voters - No - Yes

Permanent VBM Voters - No - Yes

Note: Complete results are in Table SI.7 (CA-32) and Table SI.8 (CA-40). 


\subsection{Causal Effects From Regression Discontinuity}

So far, we have estimated the effects of sending mail ballots to all registered voters using a difference-in-difference design. In this section, we take advantage of individual-level administrative records with geo-locations to conduct further analysis using a regression discontinuity design.

Table 1: Effects of Sending Mail Ballots to All Registered Voters on Voter Turnout, Regression Discontinuity Design

$$
2020
$$

2018

Est. SE Rob. SE Est. SE Rob. SE

Dependent Variable: Turnout (Indicator)

Running Variable: Distance to the Boundary

\begin{tabular}{lcccccc} 
All Districts: & & & & & & \\
Non-Perm. VBM Voters $(\mathrm{N}=363,810)$ & 2.7 & 0.4 & 0.5 & 0.9 & 0.5 & 0.5 \\
Permanent VBM Voters $(\mathrm{N}=320,454)$ & 0.0 & 0.6 & 0.7 & 0.7 & 0.7 & 0.8 \\
CA-32: & & & & & & \\
Non-Perm. VBM Voters $(\mathrm{N}=65,384)$ & 1.5 & 1.5 & 1.7 & -0.8 & 1.0 & 1.1 \\
Permanent VBM Voters $(\mathrm{N}=61,982)$ & -2.7 & 1.7 & 2.0 & -1.2 & 1.4 & 1.6 \\
CA-40: & & & & & & \\
Non-Perm. VBM Voters $(\mathrm{N}=96,929)$ & 5.1 & 0.8 & 1.0 & -1.1 & 0.9 & 1.0 \\
Permanent VBM Voters $(\mathrm{N}=78,776)$ & 1.0 & 1.3 & 1.5 & 0.0 & 1.2 & 1.4 \\
\hline
\end{tabular}

Note: Estimates from R package rdrobust using default options (local linear regressions). "SE" represents conventional standard errors, while "Rob. SE" represents robust standard errors from Calonico, Cattaneo and Titiunik (2014).

The countywide results results from the regression discontinuity design are presented in the top part of Table 1 and graphically in Figure SI.4. We find that 
non-permanent absentee voters are more likely to turn out in universal vote-bymail districts than non-universal vote-by-mail districts, by $2.7 \%$. By contrast, there is no difference in turnout among permanent absentee voters between universal vote-by-mail districts and non-universal vote-by-mail districts. As a placebo, we replaced 2020 turnout with 2018 turnout as the outcome variable in the regression discontinuity analysis. The placebo effects are statistically indistinguishable from zero (Table 1).

We again control for congressional district effects by looking at universal voteby-mail districts and non-universal vote-by-mail districts within California's 32nd and 40th congressional districts (bottom part of Table 1 and graphically in Figure SI.5 and SI.6). Like our analysis of the entire county, we find that in California's 40th congressional district, non-permanent absentee voters are more likely to turn out in the 32nd state senate district, the universal vote-bymail district, than non-universal vote-by-mail districts, by $5.1 \%$. The results are similar to those from the difference-in-difference analysis. In comparison, there is only a small and statistically insignificant difference in turnout among permanent absentee voters between the 32nd state senate district and nonuniversal vote-by-mail districts. For California's 32nd congressional district, the regression discontinuity analysis analysis has low statistical power, given the small part of the 29th state senate district inside California's 32nd congressional district (also evident from the right side of the regression discontinuity plot). That said, the point estimates are similar to what we obtained from the difference-indifference analysis with larger statistical power.

Next we look at whether sending mail ballots to all registered voters has different effects on voters of different party registrations (Table 2). First, we find 
Table 2: Effects of Sending Mail Ballots to All Registered Voters on Voter Turnout by Party Registration, Regression Discontinuity Design

\begin{tabular}{|c|c|c|c|c|c|c|}
\hline & \multicolumn{3}{|c|}{2020} & \multicolumn{3}{|c|}{2018} \\
\hline & Estimate & $\mathrm{SE}$ & Rob. SE & Estimate & $\mathrm{SE}$ & Rob. SE \\
\hline \multicolumn{7}{|c|}{ Dependent Variable: Turnout (Indicator) } \\
\hline \multicolumn{7}{|c|}{ Running Variable: Distance to the Boundary } \\
\hline \multicolumn{7}{|l|}{ Non-Perm. VBM Voters: } \\
\hline Democrats $(\mathrm{N}=186,747)$ & 4.4 & 0.6 & 0.7 & 1.5 & 0.6 & 0.7 \\
\hline Republicans (N = 62,879) & 3.1 & 1.1 & 1.3 & 2.0 & 1.0 & 1.2 \\
\hline NPA Voters $(\mathrm{N}=93,659)$ & 0.9 & 0.8 & 0.9 & 0.1 & 0.7 & 0.9 \\
\hline \multicolumn{7}{|l|}{ Permanent VBM Voters: } \\
\hline Democrats $(\mathrm{N}=167,105)$ & 1.0 & 0.8 & 1.0 & 2.0 & 0.8 & 1.0 \\
\hline Republicans (N = 50,365) & 0.4 & 1.4 & 1.7 & 1.8 & 1.3 & 1.6 \\
\hline NPA Voters $(\mathrm{N}=84,724)$ & -0.9 & 1.0 & 1.2 & 0.4 & 1.0 & 1.2 \\
\hline
\end{tabular}

Note: Estimates from R package rdrobust using default options (local linear regressions).

that the boost in turnout among non-permanent absentee voters is larger for registered Democrats and registered Republicans than voters registered without a party affiliation, which is consistent with our findings in the difference-indifference analysis. The point estimate for registered Democrats (4.4\%) is larger than for registered Republicans (3.1\%), but the difference is not statistically significant given the larger standard errors for the regression discontinuity design. It's worth noting that since the regression discontinuity design estimates the average treatment effects near the boundary, the estimates are not directly comparable to those from the difference-in-difference analysis. 


\section{Conclusion}

We have shown that the use of universal voting-by-mail in the 2020 primary election in Southern California had three implications. One is that non-permanent voters in the universal voting-by-mail areas were much more likely to vote by mail in the 2020 primary. Second, we found that for non-permanent registered voters in the universal voting-by-mail areas, sending them a ballot in the mail increased their likelihood of turning out to vote in the primary election. Generally the estimated treatment effect was consistently positive, usually statistically significant, at around 3\%.

Third, when we looked for partisan heterogeneity in the effects of universal voting-by-mail on turnout, we found that turnout increased for registered Democrats, Republicans, and those with No Party Preference. Generally, we found that turnout increased more for registered partisans (Democrats and Republicans) than for registered non-partisans (No Party Preference). Moreover, we found that in our countywide analyses, registered Republicans who were subjected to the policy were about $1.4 \%$ more likely to turnout than were registered Democrats. There is heterogeneity, though, in the partisan consequences of the policy, as in some areas we found that the registered Democrats who were subjected to the policy change were more likely to turnout than were registered Republicans. At this point, we surmise that this heterogeneity might reflect differences in the types of Democratic and Republican voters across legislative districts, an issue that merits future research.

Our study is the first that estimates the causal effect of how universal votingby-mail affects voter turnout within a jurisdiction. We do this by taking advantage of a unique aspect of election administration in the 2020 primary elections in 
Southern California. As we described in detail earlier in our paper, our withinjurisdiction design allows us to produce what we believe may be the best available estimates of the effect of universal voting-by-mail on voter turnout. Previous studies have used cross-jurisdiction designs, in situations where the transition to universal voting-by-mail has been accompanied by other changes in election administration. Our use of micro-level single-jurisdiction data, different causal inference techniques, and the examination of our data across different legislative districts help further underscore the robustness of our results.

Also, our study uses data from before the COVID-19 pandemic, which led to changes in state and county election administration later in 2020 . The pandemic led many election jurisdictions (including Los Angeles County and the State of California) to change voting procedures to minimize in-person contact and to launch new voter outreach campaigns to inform eligible citizens about safe registration and voting procedures during the general election. Unlike studies that may focus on data from the 2020 general election, when COVID-19 election administration procedures and voter information campaigns were in place, our analysis should have general applicability once pandemic-induced emergency procedures and outreach efforts are eased and lifted.

While Los Angeles County is a large and diverse election jurisdiction, and these two election cycles had their own particular characteristics, we also note that the size and diversity of Los Angeles County are comparable to (or exceed) the size and diversity of many other American states. Between the withinjurisdiction design of our study and the size and diversity of the election jurisdiction we study, we believe that our results have general applicability for other election jurisdictions considering changing to universal voting by mail. 


\section{References}

Barber, Michael and John B Holbein. 2020. “The participatory and partisan impacts of mandatory vote-by-mail." Science Advances 6(35):eabc7685.

Bonica, Adam, Jacob M Grumbach, Charlotte Hill and Hakeem Jefferson. 2021. "All-mail voting in Colorado increases turnout and reduces turnout inequality." Electoral Studies 72:102363.

Calonico, Sebastian, Matias D Cattaneo and Rocio Titiunik. 2014. "Robust nonparametric confidence intervals for regression-discontinuity designs.” Econometrica 82(6):22952326.

Gerber, Alan S, Gregory A Huber and Seth J Hill. 2013. "Identifying the effect of allmail elections on turnout: Staggered reform in the evergreen state.” Political Science Research and Methods 1(1):91-116.

Gronke, Paul and Peter Miller. 2012. "Voting by mail and turnout in Oregon: Revisiting Southwell and Burchett." American Politics Research 40(6):976-997.

Keele, Luke J and Rocio Titiunik. 2015. "Geographic boundaries as regression discontinuities.” Political Analysis 23(1):127-155.

Keele, Luke and Rocío Titiunik. 2018. “Geographic natural experiments with interference: The effect of all-mail voting on turnout in Colorado." CESifo Economic Studies 64(2):127-149.

Kousser, Thad and Megan Mullin. 2007. "Does voting by mail increase participation? Using matching to analyze a natural experiment.” Political Analysis 15(4):428-445.

Patterson, Samuel C and Gregory A Caldeira. 1985. "Mailing in the vote: Correlates and consequences of absentee voting." American Journal of Political Science pp. 766-788. 
Richey, Sean. 2008. "Voting by mail: Turnout and institutional reform in Oregon.” Social Science Quarterly 89(4):902-915.

Southwell, Priscilla and Justin Burchett. 2000. "Does changing the rules change the players? The effect of all-mail elections on the composition of the electorate." Social Science Quarterly pp. 837-845.

Thompson, Daniel M, Jennifer A Wu, Jesse Yoder and Andrew B Hall. 2020. "Universal vote-by-mail has no impact on partisan turnout or vote share." Proceedings of the National Academy of Sciences 117(25):14052-14056.

Wolfinger, Raymond E and Steven J Rosenstone. 1980. Who Votes? Yale University Press. 


\section{Supplementary Materials}

\section{SI.1. Universal Mail Elections}

Conventional wisdom about election administration in the United States (including much of the debate that occurred prior to the 2020 presidential election) seems to assume that allowing eligible citizens to obtain and cast ballots remotely is a new and untested voting procedure. Quite the contrary is the case for example, since the American Civil War, military personnel have been able to obtain and cast ballots from where they are stationed or deployed, whether by using a remote polling process, the mail, or some electronic method (Alvarez, Hall and Roberts, 2007). Different forms of remote voting have been available in most states in the more contemporary period; by the 1980s, most states allowed excuse-backed absentee voting, with three states allowing no-excuse absentee voting and one state allowing in-person early voting (Gronke et al., 2008).

The first state to implement the universal mail voting model was Oregon, which piloted tested universal mail elections in 1995 and 1996, with statewide implementation in 1998. The Oregon model has been widely studied, though whether sending every registered voter a ballot in the mail has boosted turnout in Oregon elections has been debated (Southwell and Burchett, 2000; Gronke and Miller, 2012). But the universal mail election model has been more recently adopted by Washington and Colorado (Gerber, Huber and Hill, 2013) and was used more widely during the 2020 general election due to the COVID-19 pandemic (Kamarck et al., 2020). ${ }^{5}$ Recent changes in California's election laws

\footnotetext{
${ }^{5}$ Colorado, Hawaii, Oregon, Washington, and Utah had conducted their elections almost entirely by mail before 2020. Four more states-California, Nevada, New Jersey, and Vermont-sent mail ballots to all registered voters for the November 2020 general election, so did many counties
} 
mandate that future elections in the state follow the universal voting by mail model.

In the pre-pandemic era, California began to experiment with universal mail elections through the Voter's Choice Act (VCA). In the 2018 election cycle, five California counties implemented the VCA (Madera, Napa, Nevada, Sacramento, and San Mateo). Research has found that voter turnout increased by about three percent in the VCA counties in the 2018 primaries and general elections (McGhee et al., 2020). Ten additional counties implemented the VCA in the 2020 election cycle for their statewide primary and general elections (Amador, Butte, Calaveras, El Dorado, Fresno, Los Angeles, Mariposa, Orange, Santa Clara, and Tuolumne).

Pertinent to this research is Section 4007 of the VCA, which required Los Angeles County to send mail ballots to voters who live in state legislative or federal congressional districts that span Los Angeles and other neighboring VCA counties. Our focus on this limited geographic area (Los Angeles County) is what makes our study unique in the literature. Like many of the more recent studies looking at the effects of universal voting by mail, we adopt a causal inference approach in our analysis (Gerber, Huber and Hill, 2013; Keele and Titiunik, 2018; Thompson et al., 2020; Barber and Holbein, 2020; Bonica et al., 2021). But the past studies have examined how voting by mail affects individual voters in different election administration jurisdictions, especially across counties. Even within states like Colorado, Oregon, and Washington, there is considerable variation across counties in terms of election administration, political competition and culture, and their social and demographic composition. These county-by-county differences might produce unobserved confounders, which could bias their estimates of the electoral effects of universal voting by in Montana. 
mail. Moreover, since counties usually have discretion over when or whether to opt to implement universal voting by mail, the implementation is correlated with county characteristics. ${ }^{6}$ Another important potential confounding factor is how voting by mail was typically implemented in these states, usually as part of a package of different reforms, including the elimination of neighborhood polling places and the use of an extended period of pre-election voting opportunities. Those confounding factors might make it difficult for these studies to isolate the treatment effect of universal voting by mail.

\footnotetext{
${ }^{6}$ For example, five rural counties (of 39 total counties) were the first to implement universal voting by mail in Washington State (Gerber, Huber and Hill, 2013). In the 2010 primary elections in Colorado, where counties can choose to hold all-mail elections, urban areas generally selected all-mail elections, while many rural counties chose to use in-person voting (Keele and Titiunik, 2018).
} 


\section{SI.2. Data}

For locating the congressional districts and state legislative districts in which voters reside, We match registration precincts to voting precincts using mapping created and maintained by California's Statewide Database. ${ }^{7}$ We further match voting precincts to U.S. congressional districts and California's state senate and assembly districts using the Statement of Votes available on the Los Angeles County Registrar-Recorder/County Clerk website.

For geo-locating all registered voters residing within 2 kilometers of the boundary, we first geo-located all registered voters residing in precincts within 2 kilometers of the boundary using the Google Maps API. Then we calculate the distance of each registered voter to the boundary using their geo-location and restrict attention to those residing within 2 kilometers of the boundary.

\footnotetext{
${ }^{7}$ See https://statewidedatabase.org/.
} 
Figure SI.1: Districts with and without Universal VBM in Los Angeles County

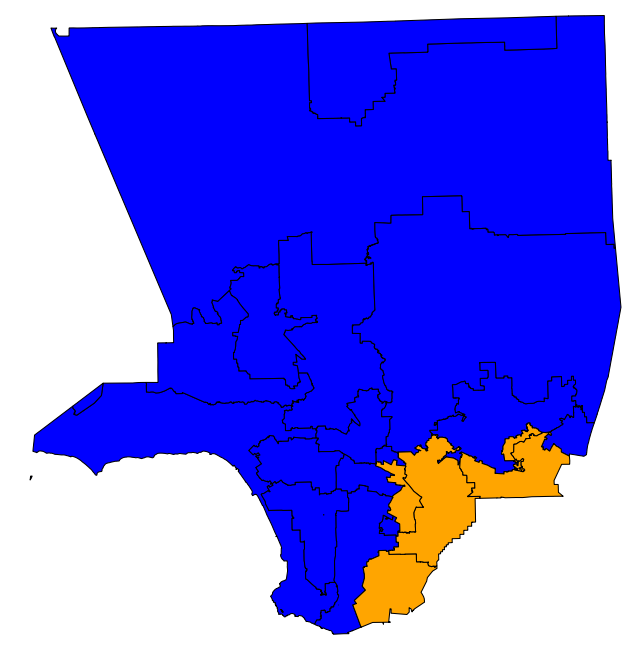

Note: Universal vote-by-mail districts (in orange) include California's 38th, 39th, and 47th congressional districts, as well as parts of California's 32nd and 40th congressional districts (29th and 32nd state senate districts). The rest of Los Angeles County are nonuniversal vote-by-mail districts (in blue). 
Figure SI.2: Districts with and without Universal VBM in CA-32 and CA-40
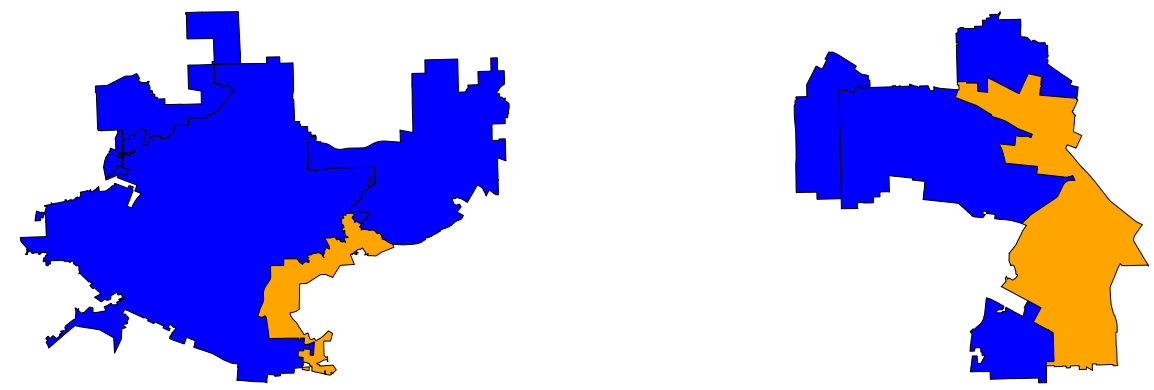

Note: The universal vote-by-mail district within California's 32nd congressional district (left) is the area within the 29th state senate district (in orange). The universal vote-by-mail district within California's 40th congressional district (right) is the area within the 32nd state senate district (in orange). The rest of California's 32nd and 40th congressional districts are non-universal vote-by-mail districts (in blue). For California's 32nd congressional district, we note that the congressional district also contains the 55th state assembly district that includes areas in Los Angeles County and Orange County, but the portion of the 55th state assembly district in Los Angeles County coincides with the 29th state senate district. 


\section{SI.3. Trends in Voter Turnout}

In this section, we examine the trends in universal and non-universal vote-bymail districts in election cycles before the policy was implemented. Figure SI.3 shows the voter turnout among all registered voters in universal vote-by-mail districts (blue) and non-universal vote-by-mail districts (orange) in primary elections from 2012 to 2020 . We can see that in both presidential primary years prior to the policy, 2012 and 2016, voter turnout was around 2\% lower in universal vote-by-mail districts than non-universal vote-by-mail districts. Meanwhile, in both statewide primary years without a presidential contest, 2014 and 2018, voter turnout was virtually the same in universal and non-universal vote-by-mail districts. These observations support the parallel trends assumption for our difference-in-difference design. Absent the policy, one would expect the turnout (both in absolute terms and relative to 2018) to be lower in universal vote-by-mail districts than non-universal vote-by-mail districts in 2020. 
Figure SI.3: Pre-Policy Trends in Universal and Non-Universal VBM Districts in Los Angeles County in Presidential Years and Midterm Years

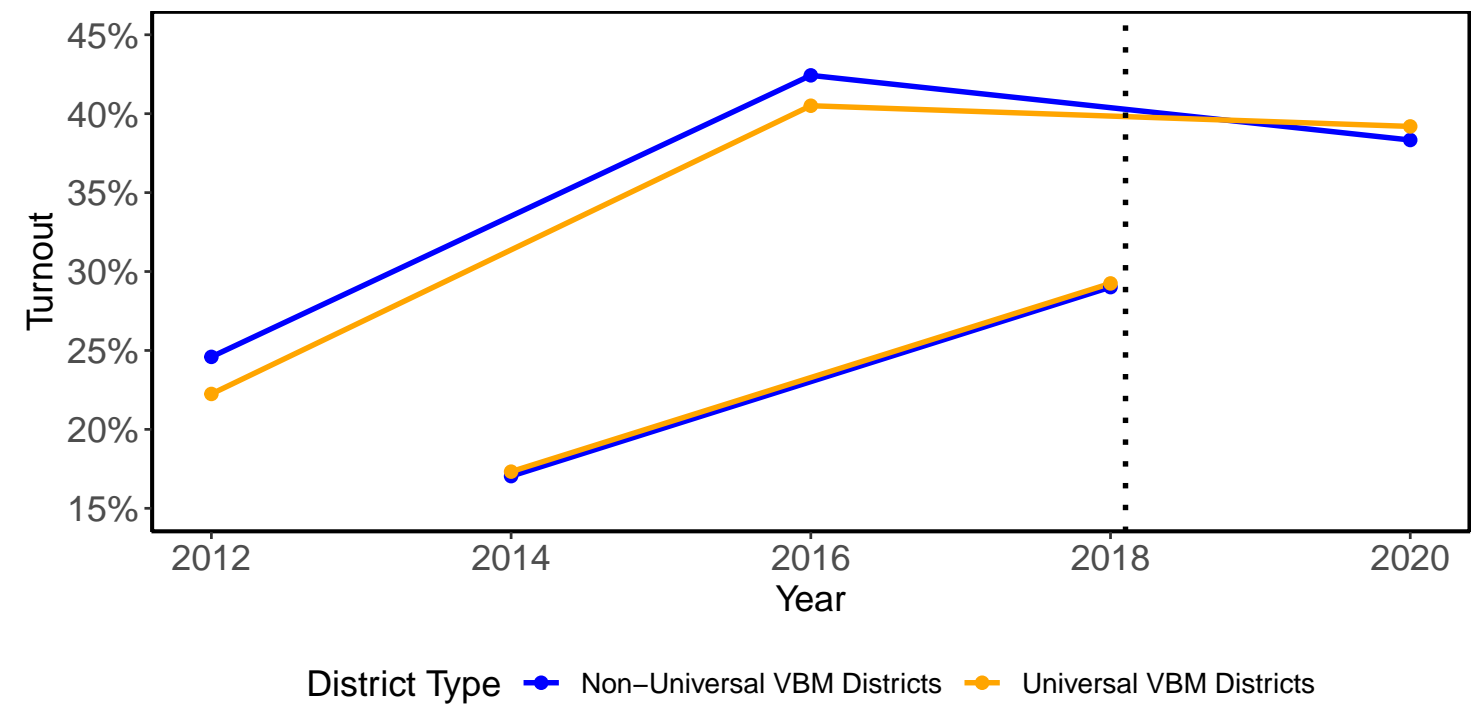

Note: Universal VBM Districts refer to congressional districts and state legislative districts where all registered voters automatically receive a ballot in the mail in the 2020 primary elections, shown in orange in Figure SI.1. The orange lines trace turnout in these districts before they were made universal vote-by-mail in 2020. Similarly, the blue lines trace the turnouts in districts that are not universal vote-by-mail in 2020 . Turnout in the districts is computed using data from the Statements of Votes. 


\section{SI.4. Voter Demographics in Universal and Non-Universal Vote-by-Mail Districts}

In this section, we examine voter demographics in universal and non-universal vote-by-mail districts in Table SI.1. The global $\chi^{2}$ statistic indicates that balance improves as we focus on voters living closer to the boundary. Our finding that distance to the boundary improves but does not remove all the imbalances is a common phenomenon in geographic applications (Keele and Titiunik, 2015). To examine each demographic variable separately, we ran the regression discontinuity design using each demographic variable as the outcome variable. The results from these placebo analyses are presented in Table SI.2. Among nonpermanent absentee voters, there is no difference in terms of average age and female proportions between universal and non-universal vote-by-mail districts. As for race/ethnicity, there are $1.4 \%$ non-Hispanic white voters in universal voteby-mail districts than non-universal vote-by-mail districts. The same difference, however, is present among permanent absentee voters as well. 
Table SI.1: Demographic Balance between Universal and Non-Universal VBM Districts as a Function of Distance

\begin{tabular}{lrrrrr}
\hline & $2 \mathrm{~km}$ & $1 \mathrm{~km}$ & $500 \mathrm{~m}$ & $200 \mathrm{~m}$ & $100 \mathrm{~m}$ \\
\hline Non-PVBM Voters: & & & & & \\
$\chi^{2}$ Statistic & 6,045 & 2,487 & 1,207 & 303 & 105 \\
UVBM sample size & 169,447 & 93,156 & 49,211 & 21,672 & 11,250 \\
Non-UVBM sample size & 194,363 & 103,557 & 58,726 & 24,396 & 11,255 \\
\hline PVBM Voters: & & & & & \\
$\chi^{2}$ Statistic & 7,587 & 3,057 & 1,399 & 262 & 66 \\
UVBM sample size & 155,361 & 83,589 & 43,084 & 18,677 & 9,735 \\
Non-UVBM sample size & 165,093 & 87,885 & 49,828 & 21,151 & 9,885 \\
\hline
\end{tabular}

Note: The metric is the $\chi^{2}$ test statistic from a global balance test applied to demographic covariates, including age, gender, and race/ethnicity. For gender, we use (in descending order of priority) (1) voter-provided gender, (2) voter-provided title (Mr., Mrs., Miss., Ms.), (3) inferred probability from the first name, or (4) inferred probability from the middle name. Probabilities in (3) and (4) are produced with R package gender. For race/ethnicity, we use inferred probabilities of different race/ethnicity categories from the last name (together with age, gender, and party id) using R package $w r u$. 
Table SI.2: Placebo Estimates Using Demographic Variables as Outcome Variables in Regression Discontinuity Design

\begin{tabular}{lrlrrrrr}
\hline & \multicolumn{3}{c}{ Non-Perm. VBM Voters } & \multicolumn{3}{c}{ Permanent VBM Voters } \\
& Estimate & SE & Rob. SE & Estimate & SE & Rob. SE \\
\hline Age & 0.25 & 0.31 & 0.38 & -0.07 & 0.33 & 0.40 \\
Gender (\%. Female) & -0.36 & 0.71 & 0.84 & 0.14 & 0.78 & 0.92 \\
Race (\% Non-Hisp. White) & 1.37 & 0.58 & 0.65 & 1.26 & 0.54 & 0.62 \\
\hline
\end{tabular}

Note: All results are estimated with R package rdrobust. "SE" represents conventional standard errors, while "Rob. SE" represents robust standard errors described in Calonico, Cattaneo and Titiunik (2014) (see Calonico, Cattaneo and Titiunik (2014) for details). See the note under Table SI.1 for details regarding the demographic variables. 
SI.5. Additional Tables and Figures For Section 3 
Table SI.3: Effects of Sending Mail Ballots to All Registered Voters on Percent of Voters Voting by Mail and Voter Turnout, All Districts in Los Angeles County

\begin{tabular}{|c|c|c|c|c|}
\hline & 2018 & 2020 & Difference & Diff-in-Diff \\
\hline \multicolumn{5}{|c|}{ Dependent Variable: Voting by Mail (Indicator) } \\
\hline \multicolumn{5}{|c|}{ Non-Permanent VBM Voters $(\mathrm{N}=1, \mathbf{1 8 4 , 2 9 0}$ Voter $\times$ Year $)$} \\
\hline \multirow[t]{2}{*}{ Universal VBM Districts } & 6.4 & 44.5 & 38.1 & 41.9 \\
\hline & $(0.09)$ & $(0.08)$ & $(0.12)$ & $(0.13)$ \\
\hline \multirow[t]{2}{*}{ Non-Universal VBM Districts } & 7.1 & 3.4 & -3.8 & \\
\hline & $(0.04)$ & $(0.03)$ & $(0.05)$ & \\
\hline \multicolumn{5}{|c|}{ 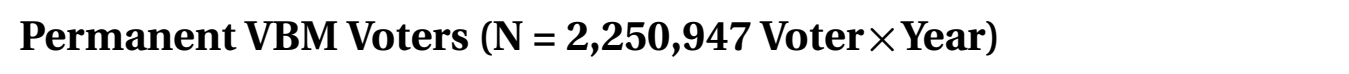 } \\
\hline \multirow[t]{2}{*}{ Universal VBM Districts } & 82.9 & 77.2 & -5.7 & 1.4 \\
\hline & $(0.11)$ & $(0.09)$ & $(0.15)$ & $(0.16)$ \\
\hline \multirow[t]{2}{*}{ Non-Universal VBM Districts } & 82.4 & 75.3 & -7.1 & \\
\hline & $(0.05)$ & $(0.04)$ & $(0.06)$ & \\
\hline
\end{tabular}

Dependent Variable: Turnout (Indicator)

Non-Permanent VBM Voters $(\mathrm{N}=4, \mathbf{7 8 8 , 9 3 8}$ Reg. Voter $\times$ Year $)$

\begin{tabular}{lcccc}
\hline Universal VBM Districts & 22.2 & 31.8 & 9.6 & 3.3 \\
& $(0.07)$ & $(0.07)$ & $(0.1)$ & $(0.11)$ \\
Non-Universal VBM Districts & 21.1 & 27.5 & 6.4 & \\
& $(0.03)$ & $(0.03)$ & $(0.04)$ & \\
\hline Permanent VBM Voters (N = 6,288,850 & Reg. Voter $\times$ Year) & \\
\hline Universal VBM Districts & 26.7 & 43.3 & 16.7 & -1.8 \\
\multirow{2}{*}{ Non-Universal VBM Districts } & 26.7 & 45.2 & 18.5 & $(0.1)$ \\
& $(0.03)$ & $(0.03)$ & $(0.04)$ & \\
\hline
\end{tabular}

Note: Diff-in-diff estimates are from models I(Voting by Mail $)=\alpha+\beta_{\text {UVBM }} \mathrm{I}(\mathrm{UVBM})+$ $\beta_{2020} \mathrm{I}(2020)+\beta_{D i D} \mathrm{I}(\mathrm{UVBM}) \mathrm{I}(2020)+\epsilon$ and $\mathrm{I}($ Turnout $)=\alpha+\beta_{\text {UVBM }} \mathrm{I}(\mathrm{UVBM})+$ $\beta_{2020} \mathrm{I}(2020)+\beta_{D i D} \mathrm{I}(\mathrm{UVBM}) \mathrm{I}(2020)+\epsilon$. Numbers in the table are precentage points. 
Table SI.4: Effects of Sending Mail Ballots to All Registered Voters on Voter Turnout by Party Registration, All Districts in Los Angeles County

\begin{tabular}{|c|c|c|c|c|c|c|c|c|c|}
\hline & \multicolumn{3}{|c|}{ Dem Voters } & \multicolumn{3}{|c|}{ Rep Voters } & \multicolumn{3}{|c|}{ NPA Voters } \\
\hline & 2018 & 2020 & Diff & 2018 & 2020 & Diff & 2018 & 2020 & Diff \\
\hline \multicolumn{10}{|c|}{ Dependent Variable: Turnout (Indicator) } \\
\hline \multicolumn{10}{|c|}{ Non-Permanent VBM Voters } \\
\hline \multirow[t]{2}{*}{ UVBM Districts } & 24.9 & 37.8 & 12.9 & 30.3 & 36.3 & 6.0 & 12.9 & 19.7 & 6.8 \\
\hline & $(0.11)$ & $(0.11)$ & $(0.15)$ & $(0.17)$ & $(0.17)$ & $(0.24)$ & $(0.12)$ & $(0.12)$ & $(0.16)$ \\
\hline \multirow[t]{2}{*}{ Non-UVBM Districts } & 24.9 & 34.0 & 9.2 & 27.0 & 27.9 & 0.2 & 12.5 & 17.2 & 4.7 \\
\hline & $(0.04)$ & $(0.04)$ & $(0.06)$ & $(0.08)$ & $(0.08)$ & $(0.11)$ & $(0.05)$ & $(0.05)$ & $(0.07)$ \\
\hline \multirow[t]{3}{*}{ Diff-in-Diff } & & & 3.8 & & & 5.2 & & & 2.1 \\
\hline & & & $(0.17)$ & & & $(0.26)$ & & & $(0.18)$ \\
\hline & \multicolumn{3}{|c|}{$\mathrm{N}=2,434,046$} & \multicolumn{3}{|c|}{$\mathrm{N}=797,800$} & \multicolumn{3}{|c|}{$\mathrm{N}=1,302,838$} \\
\hline \multicolumn{10}{|c|}{ Permanent VBM Voters } \\
\hline \multirow[t]{2}{*}{ UVBM Districts } & 27.6 & 49.3 & 21.6 & 38.1 & 51.0 & 12.9 & 17.9 & 28.9 & 11.0 \\
\hline & $(0.1)$ & $(0.1)$ & $(0.14)$ & $(0.16)$ & $(0.16)$ & $(0.22)$ & $(0.12)$ & $(0.12)$ & $(0.17)$ \\
\hline \multirow[t]{2}{*}{ Non-UVBM Districts } & 29.1 & 52.3 & 23.2 & 35.9 & 49.5 & 13.6 & 17.6 & 30.0 & 12.5 \\
\hline & $(0.04)$ & $(0.04)$ & $(0.06)$ & $(0.07)$ & $(0.07)$ & $(0.1)$ & $(0.05)$ & $(0.05)$ & $(0.07)$ \\
\hline \multirow[t]{3}{*}{ Diff-in-Diff } & & & -1.6 & & & -0.7 & & & -1.5 \\
\hline & & & $(0.15)$ & & & $(0.25)$ & & & $(0.19)$ \\
\hline & \multicolumn{3}{|c|}{$\mathrm{N}=3,320,848$} & \multicolumn{3}{|c|}{$N=1,069,668$} & \multicolumn{3}{|c|}{$\mathrm{N}=1,550,120$} \\
\hline
\end{tabular}

Note: Diff-in-diff estimates are from models I(Voting by Mail $)=\alpha+\beta_{\text {UVBM }} \mathrm{I}(\mathrm{UVBM})+$ $\beta_{2020} \mathrm{I}(2020)+\beta_{D i D} \mathrm{I}(\mathrm{UVBM}) \mathrm{I}(2020)+\epsilon$ and $\mathrm{I}($ Turnout $)=\alpha+\beta_{\text {UVBM }} \mathrm{I}(\mathrm{UVBM})+$ $\beta_{2020} \mathrm{I}(2020)+\beta_{D i D} \mathrm{I}(\mathrm{UVBM}) \mathrm{I}(2020)+\epsilon$. Numbers in the table are precentage points. 
Table SI.5: Effects of Sending Mail Ballots to All Registered Voters on Percent of Voters Voting by Mail and Voter Turnout, CA-32

\begin{tabular}{|c|c|c|c|c|}
\hline & 2018 & 2020 & Difference & Diff-in-Diff \\
\hline \multicolumn{5}{|c|}{ Dependent Variable: Voting by Mail (Indicator) } \\
\hline \multicolumn{5}{|c|}{ Non-Permanent VBM Voters $(\mathrm{N}=\mathbf{7 8 , 3 8 1}$ Voter $\times$ Year $)$} \\
\hline \multirow[t]{2}{*}{ Universal VBM Districts } & 7.1 & 45.7 & 38.6 & 42.5 \\
\hline & $(0.56)$ & $(0.47)$ & $(0.73)$ & $(0.74)$ \\
\hline \multirow[t]{2}{*}{ Non-Universal VBM Districts } & 6.3 & 2.4 & -3.9 & \\
\hline & $(0.12)$ & $(0.1)$ & $(0.16)$ & \\
\hline \multicolumn{5}{|c|}{ Permanent VBM Voters $(\mathrm{N}=128,121$ Voter $\times$ Year $)$} \\
\hline \multirow[t]{2}{*}{ Universal VBM Districts } & 81.8 & 77.3 & -4.5 & 5 \\
\hline & $(0.84)$ & $(0.66)$ & $(1.07)$ & $(1.1)$ \\
\hline \multirow[t]{2}{*}{ Non-Universal VBM Districts } & 81.4 & 71.9 & -9.4 & \\
\hline & $(0.2)$ & $(0.15)$ & $(0.25)$ & \\
\hline
\end{tabular}

Dependent Variable: Turnout (Indicator)

Non-Permanent VBM Voters $(\mathrm{N}=309,714$ Reg. Voter $\times$ Year $)$

\begin{tabular}{lcccc}
\hline Universal VBM Districts & 21.4 & 30.5 & 9.2 & 2 \\
& $(0.53)$ & $(0.53)$ & $(0.75)$ & $(0.77)$ \\
Non-Universal VBM Districts & 21.7 & 28.9 & 7.2 & \\
& $(0.11)$ & $(0.11)$ & $(0.16)$ & \\
\hline \multirow{2}{*}{ Permanent VBM Voters (N = } & $\mathbf{4 0 1 , 0 4 8}$ & Reg. Voter $\times$ Year) & \\
\hline Universal VBM Districts & 25.6 & 41.5 & 15.9 & -0.8 \\
& $(0.46)$ & $(0.46)$ & $(0.65)$ & $(0.66)$ \\
Non-Universal VBM Districts & 23.5 & 40.2 & 16.7 & \\
& $(0.11)$ & $(0.11)$ & $(0.15)$ & \\
\hline
\end{tabular}

Note: Diff-in-diff estimates are from models I(Voting by Mail $)=\alpha+\beta_{\text {UVBM }} \mathrm{I}(\mathrm{UVBM})+$ $\beta_{2020} \mathrm{I}(2020)+\beta_{D i D} \mathrm{I}(\mathrm{UVBM}) \mathrm{I}(2020)+\epsilon$ and $\mathrm{I}($ Turnout $)=\alpha+\beta_{\text {UVBM }} \mathrm{I}(\mathrm{UVBM})+$ $\beta_{2020} \mathrm{I}(2020)+\beta_{D i D} \mathrm{I}(\mathrm{UVBM}) \mathrm{I}(2020)+\epsilon$. Numbers in the table are precentage points. 
Table SI.6: Effects of Sending Mail Ballots to All Registered Voters on Percent of Voters Voting by Mail and Voter Turnout, CA-40

\begin{tabular}{|c|c|c|c|c|}
\hline & 2018 & 2020 & Difference & Diff-in-Diff \\
\hline \multicolumn{5}{|c|}{ Dependent Variable: Voting by Mail (Indicator) } \\
\hline \multicolumn{5}{|c|}{ Non-Permanent VBM Voters $(\mathrm{N}=\mathbf{5 6 , 4 4 5}$ Voter $\times$ Year $)$} \\
\hline \multirow[t]{2}{*}{ Universal VBM Districts } & 6.1 & 43.6 & 37.5 & 41.8 \\
\hline & $(0.32)$ & $(0.27)$ & $(0.42)$ & $(0.52)$ \\
\hline \multirow[t]{2}{*}{ Non-Universal VBM Districts } & 6.4 & 2.1 & -4.3 & \\
\hline & $(0.23)$ & $(0.2)$ & $(0.31)$ & \\
\hline \multicolumn{5}{|c|}{ Permanent VBM Voters $(\mathrm{N}=75,420$ Voter $\times$ Year $)$} \\
\hline \multirow[t]{2}{*}{ Universal VBM Districts } & 79.3 & 72.7 & -6.6 & 10.7 \\
\hline & $(0.45)$ & $(0.35)$ & $(0.57)$ & $(0.72)$ \\
\hline \multirow[t]{2}{*}{ Non-Universal VBM Districts } & 79.2 & 61.9 & -17.3 & \\
\hline & $(0.36)$ & $(0.25)$ & $(0.44)$ & \\
\hline
\end{tabular}

Dependent Variable: Turnout (Indicator)

Non-Permanent VBM Voters $(\mathrm{N}=\mathbf{2 9 5 , 5 7 2}$ Reg. Voter $\times$ Year)

\begin{tabular}{lcccc}
\hline Universal VBM Districts & 19.9 & 29.2 & 9.2 & 3.7 \\
& $(0.19)$ & $(0.19)$ & $(0.27)$ & $(0.32)$ \\
Non-Universal VBM Districts & 14.3 & 19.8 & 5.5 & \\
& $(0.12)$ & $(0.12)$ & $(0.17)$ & \\
\hline Permanent VBM Voters (N = & $\mathbf{3 0 3 , 7 6 2}$ & Reg. Voter $\times$ Year) & \\
\hline Universal VBM Districts & 21.2 & 36.1 & 15 & -1.6 \\
\multirow{4}{*}{ Non-Universal VBM Districts } & 14.8 & 31.4 & 16.5 & \\
& $(0.13)$ & $(0.13)$ & $(0.19)$ & \\
\hline
\end{tabular}

Note: Diff-in-diff estimates are from models I(Voting by Mail $)=\alpha+\beta_{\text {UVBM }} \mathrm{I}(\mathrm{UVBM})+$ $\beta_{2020} \mathrm{I}(2020)+\beta_{D i D} \mathrm{I}(\mathrm{UVBM}) \mathrm{I}(2020)+\epsilon$ and $\mathrm{I}($ Turnout $)=\alpha+\beta_{\text {UVBM }} \mathrm{I}(\mathrm{UVBM})+$ $\beta_{2020} \mathrm{I}(2020)+\beta_{D i D} \mathrm{I}(\mathrm{UVBM}) \mathrm{I}(2020)+\epsilon$. Numbers in the table are precentage points. 
Table SI.7: Effects of Sending Mail Ballots to All Registered Voters on Voter Turnout by Party Registration, CA-32

\begin{tabular}{|c|c|c|c|c|c|c|c|c|c|}
\hline & \multicolumn{3}{|c|}{ Dem Voters } & \multicolumn{3}{|c|}{ Rep Voters } & \multicolumn{3}{|c|}{ NPA Voters } \\
\hline & 2018 & 2020 & Diff & 2018 & 2020 & Diff & 2018 & 2020 & Diff \\
\hline \multicolumn{10}{|c|}{ Dependent Variable: Turnout (Indicator) } \\
\hline \multicolumn{10}{|c|}{ Non-Permanent VBM Voters } \\
\hline \multirow[t]{2}{*}{ UVBM Districts } & 25.9 & 37.9 & 12.1 & 28.9 & 36.6 & 7.6 & 11.4 & 18.0 & 6.6 \\
\hline & $(0.86)$ & $(0.86)$ & $(1.21)$ & $(1.22)$ & $(1.22)$ & $(1.73)$ & $(0.79)$ & $(0.79)$ & $(1.12)$ \\
\hline \multirow[t]{2}{*}{ Non-UVBM Districts } & 24.4 & 34.7 & 10.3 & 30.0 & 33.1 & 3.1 & 12.4 & 17.8 & 5.4 \\
\hline & $(0.17)$ & $(0.17)$ & $(0.24)$ & $(0.26)$ & $(0.26)$ & $(0.37)$ & $(0.18)$ & $(0.18)$ & $(0.25)$ \\
\hline \multirow[t]{3}{*}{ Diff-in-Diff } & & & 1.8 & & & 4.6 & & & 1.2 \\
\hline & & & $(1.24)$ & & & $(1.77)$ & & & (1.15) \\
\hline & \multicolumn{3}{|c|}{$\mathrm{N}=144,782$} & \multicolumn{3}{|c|}{$\mathrm{N}=64,564$} & \multicolumn{3}{|c|}{$\mathrm{N}=83,644$} \\
\hline \multicolumn{10}{|l|}{ Permanent VBM Voters } \\
\hline \multirow[t]{2}{*}{ UVBM Districts } & 26.6 & 47.1 & 20.5 & 35.9 & 50.1 & 14.2 & 17.8 & 28.1 & 10.4 \\
\hline & $(0.69)$ & $(0.69)$ & $(0.98)$ & $(1.06)$ & $(1.06)$ & $(1.49)$ & $(0.75)$ & $(0.75)$ & $(1.07)$ \\
\hline \multirow[t]{2}{*}{ Non-UVBM Districts } & 24.4 & 45.2 & 20.8 & 35.2 & 49.8 & 14.6 & 14.6 & 26.0 & 11.4 \\
\hline & $(0.15)$ & $(0.15)$ & $(0.22)$ & $(0.25)$ & $(0.25)$ & $(0.35)$ & $(0.18)$ & $(0.18)$ & $(0.26)$ \\
\hline \multirow[t]{3}{*}{ Diff-in-Diff } & & & -0.3 & & & -0.4 & & & -1.1 \\
\hline & & & (1) & & & $(1.53)$ & & & $(1.1)$ \\
\hline & \multicolumn{3}{|c|}{$N=193,808$} & \multicolumn{3}{|c|}{$\mathrm{N}=80,468$} & \multicolumn{3}{|c|}{$\mathrm{N}=102,614$} \\
\hline
\end{tabular}

Note: Diff-in-diff estimates are from models I(Voting by Mail $)=\alpha+\beta_{\text {UVBM }} \mathrm{I}(\mathrm{UVBM})+$ $\beta_{2020} \mathrm{I}(2020)+\beta_{D i D} \mathrm{I}(\mathrm{UVBM}) \mathrm{I}(2020)+\epsilon$ and $\mathrm{I}($ Turnout $)=\alpha+\beta_{\text {UVBM }} \mathrm{I}(\mathrm{UVBM})+$ $\beta_{2020} \mathrm{I}(2020)+\beta_{D i D} \mathrm{I}(\mathrm{UVBM}) \mathrm{I}(2020)+\epsilon$. Numbers in the table are precentage points. 
Table SI.8: Effects of Sending Mail Ballots to All Registered Voters on Voter Turnout by Party Registration, CA-40

\begin{tabular}{|c|c|c|c|c|c|c|c|c|c|}
\hline & \multicolumn{3}{|c|}{ Dem Voters } & \multicolumn{3}{|c|}{ Rep Voters } & \multicolumn{3}{|c|}{ NPA Voters } \\
\hline & 2018 & 2020 & Diff & 2018 & 2020 & Diff & 2018 & 2020 & Diff \\
\hline \multicolumn{10}{|c|}{ Dependent Variable: Turnout (Indicator) } \\
\hline \multicolumn{10}{|c|}{ Non-Permanent VBM Voters } \\
\hline \multirow[t]{2}{*}{ UVBM Districts } & 22.1 & 34.7 & 12.6 & 27.6 & 32.1 & 4.5 & 11.3 & 17.9 & 6.5 \\
\hline & $(0.29)$ & $(0.29)$ & $(0.4)$ & $(0.47)$ & $(0.47)$ & $(0.66)$ & $(0.32)$ & $(0.32)$ & $(0.45)$ \\
\hline \multirow[t]{2}{*}{ Non-UVBM Districts } & 17.5 & 24.0 & 6.5 & 12.6 & 14.0 & 1.5 & 8.7 & 13.0 & 4.3 \\
\hline & $(0.16)$ & $(0.16)$ & $(0.23)$ & $(0.46)$ & $(0.46)$ & $(0.65)$ & $(0.19)$ & $(0.19)$ & $(0.27)$ \\
\hline \multirow[t]{3}{*}{ Diff-in-Diff } & & & 6.1 & & & 3.1 & & & 2.2 \\
\hline & & & $(0.47)$ & & & $(0.92)$ & & & $(0.53)$ \\
\hline & \multicolumn{3}{|c|}{$\mathrm{N}=172,750$} & \multicolumn{3}{|c|}{$\mathrm{N}=30,254$} & \multicolumn{3}{|c|}{$\mathrm{N}=77,508$} \\
\hline \multicolumn{10}{|c|}{ Permanent VBM Voters } \\
\hline \multirow[t]{2}{*}{ UVBM Districts } & 22.1 & 41.8 & 19.6 & 32.4 & 42.8 & 10.4 & 12.8 & 22.3 & 9.4 \\
\hline & $(0.28)$ & $(0.28)$ & $(0.4)$ & $(0.5)$ & $(0.5)$ & $(0.71)$ & $(0.34)$ & $(0.34)$ & $(0.47)$ \\
\hline \multirow[t]{2}{*}{ Non-UVBM Districts } & 17.2 & 36.8 & 19.6 & 19.1 & 31.1 & 12.0 & 9.3 & 20.1 & 10.8 \\
\hline & $(0.17)$ & $(0.17)$ & $(0.24)$ & $(0.57)$ & $(0.57)$ & $(0.8)$ & $(0.22)$ & $(0.22)$ & $(0.31)$ \\
\hline \multirow[t]{3}{*}{ Diff-in-Diff } & & & 0 & & & -1.6 & & & -1.4 \\
\hline & & & $(0.46)$ & & & $(1.07)$ & & & $(0.57)$ \\
\hline & \multicolumn{3}{|c|}{$\mathrm{N}=181,676$} & \multicolumn{3}{|c|}{$\mathrm{N}=30,086$} & \multicolumn{3}{|c|}{$N=75,072$} \\
\hline
\end{tabular}

Note: Diff-in-diff estimates are from models I(Voting by Mail $)=\alpha+\beta_{\text {UVBM }} \mathrm{I}(\mathrm{UVBM})+$ $\beta_{2020} \mathrm{I}(2020)+\beta_{D i D} \mathrm{I}(\mathrm{UVBM}) \mathrm{I}(2020)+\epsilon$ and $\mathrm{I}($ Turnout $)=\alpha+\beta_{\text {UVBM }} \mathrm{I}(\mathrm{UVBM})+$ $\beta_{2020} \mathrm{I}(2020)+\beta_{D i D} \mathrm{I}(\mathrm{UVBM}) \mathrm{I}(2020)+\epsilon$. Numbers in the table are precentage points. 
Figure SI.4: Effects of Sending Mail Ballots to All Registered Voters on Voter Turnout, Regression Discontinuity Design
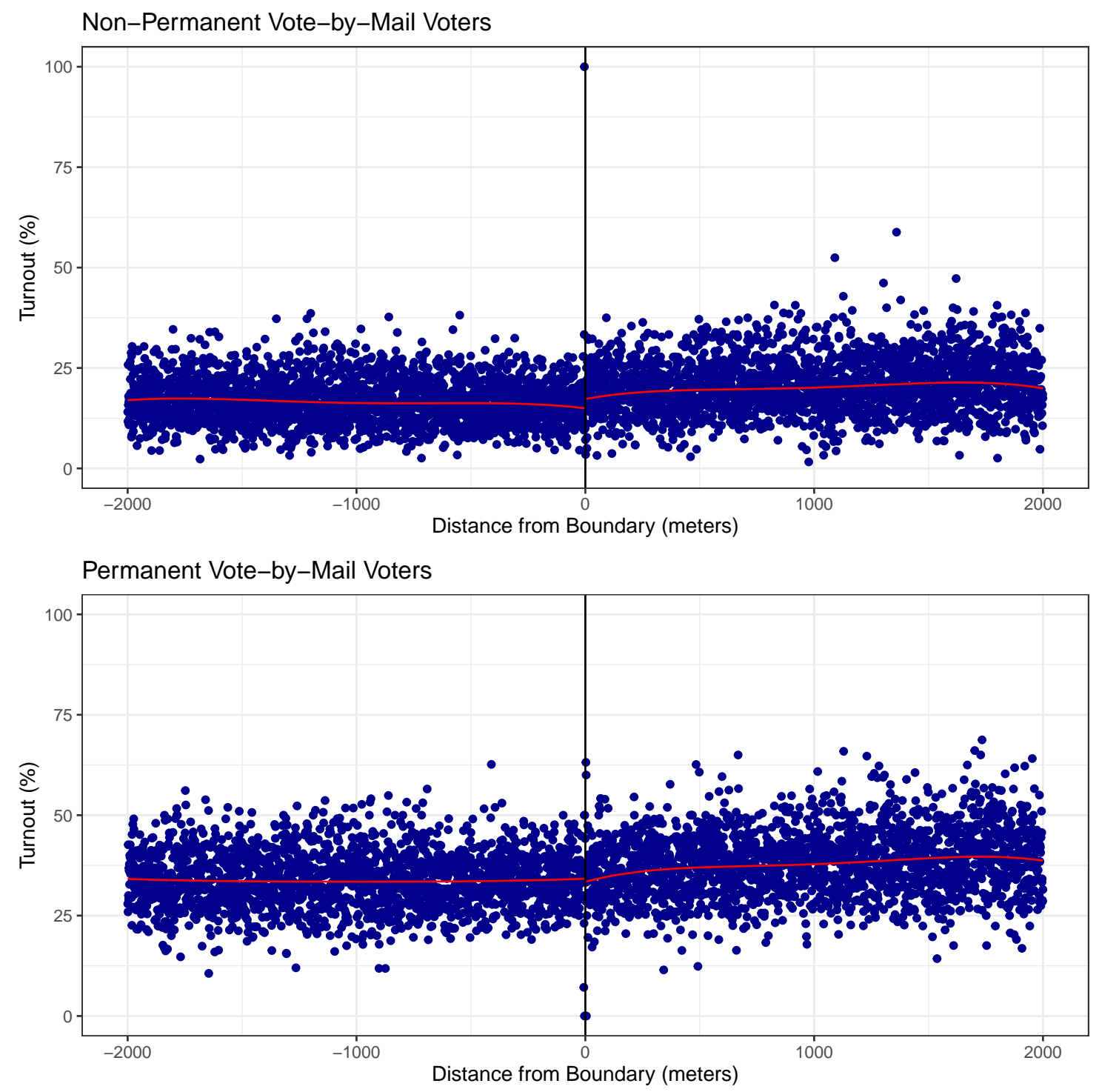

Note: The regression discontinuity plots are produced with R package rdrobust using its default options. The points represent the binned sample means of the outcome, and the curves represent the fourth-order polynomial regression estimates for control and treatment units separately. Within 2 kilometers of the boundary, there are 194,363 non-PVBM voters in non-UVBM districts, 169,447 non-PVBM voters in UVBM districts, 165,093 PVBM voters in non-UVBM districts, and 155,361 PVBM voters in UVBM districts. 
Figure SI.5: Effects of Sending Mail Ballots to All Registered Voters on Voter Turnout, CA-32, Regression Discontinuity Design
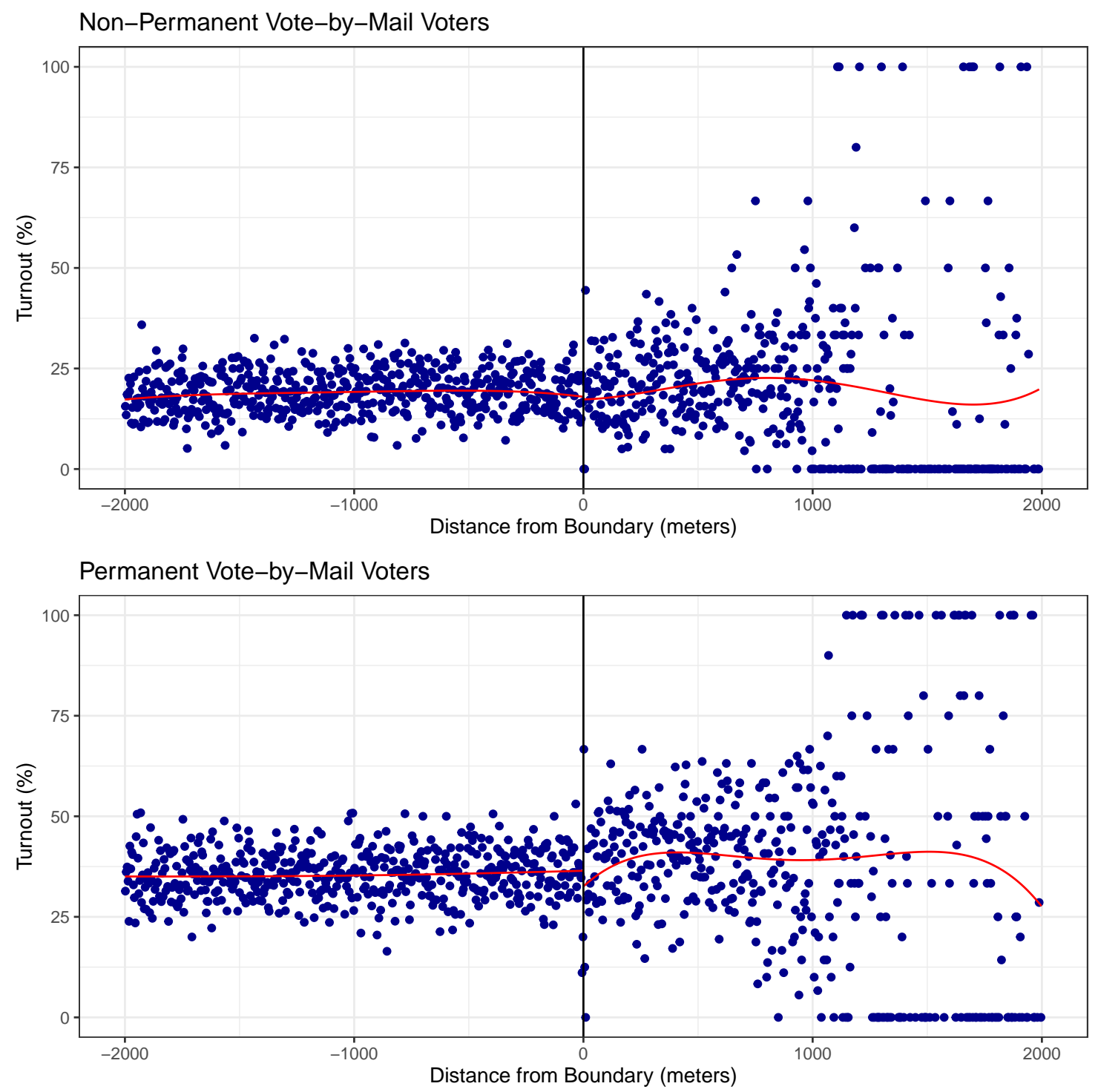

Note: The regression discontinuity plots are produced with R package rdrobust using its default options. The points represent the binned sample means of the outcome, and the curves represent the fourth-order polynomial regression estimates for control and treatment units separately. Within 2 kilometers of the boundary, there are 55,151 non-PVBM voters in non-UVBM districts, 10,233 non-PVBM voters in UVBM districts, 51,344 PVBM voters in non-UVBM districts, and 10,638 PVBM voters in UVBM districts. 
Figure SI.6: Effects of Sending Mail Ballots to All Registered Voters on Voter Turnout, CA-40, Regression Discontinuity Design
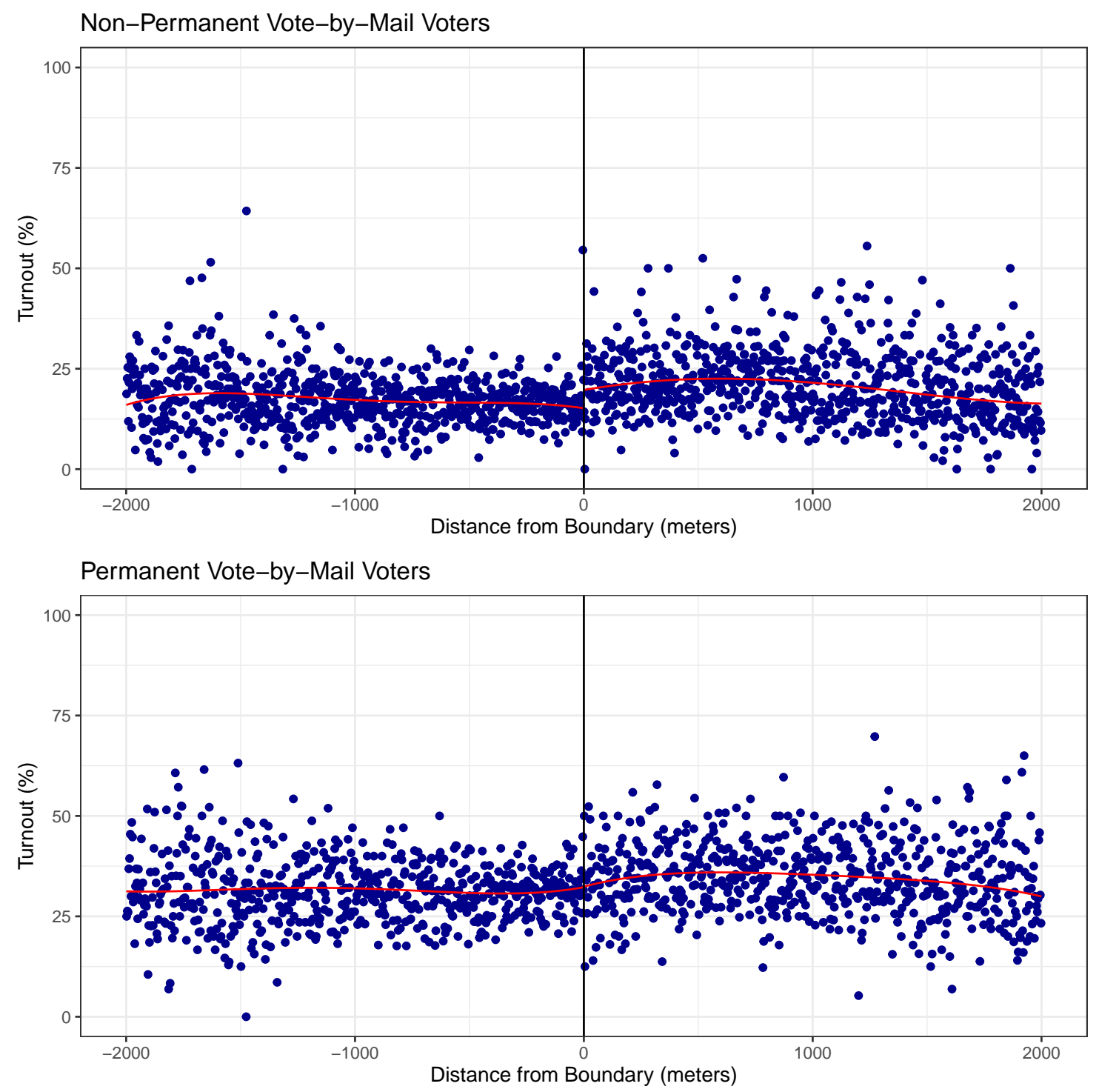

Note: The regression discontinuity plots are produced with R package rdrobust using its default options. The points represent the binned sample means of the outcome, and the curves represent the fourth-order polynomial regression estimates for control and treatment units separately. Within 2 kilometers of the boundary, there are 59,115 non-PVBM voters in non-UVBM districts, 37,814 non-PVBM voters in UVBM districts, 46,992 PVBM voters in non-UVBM districts, and 31,784 PVBM voters in UVBM districts. 


\section{SI.6. Exploring Heterogeneous Treatment Effects along the Boundary}

In this section, we estimate the effects of sending mail ballots to all registered voters on voter turnout for different points along the boundary of universal and non-universal vote-by-mail districts using the approach proposed in Keele and Titiunik (2015). Given that the boundary stretches over 180 kilometers and is situated between eight different congressional districts, we expect some heterogeneity for different points along the boundary. Figure SI.7 presents the results. Focusing on voters residing close to a point on the boundary reduces the sample size significantly and leads this analysis to be underpowered for the size of treatment effects we expect. That said, this exploratory analysis suggests that the policy's effect on turnout is heterogeneous along the boundary. 
Figure SI.7: Effects of Sending Mail Ballots to All Registered Voters on Voter Turnout, Keele and Titiunik (2015)
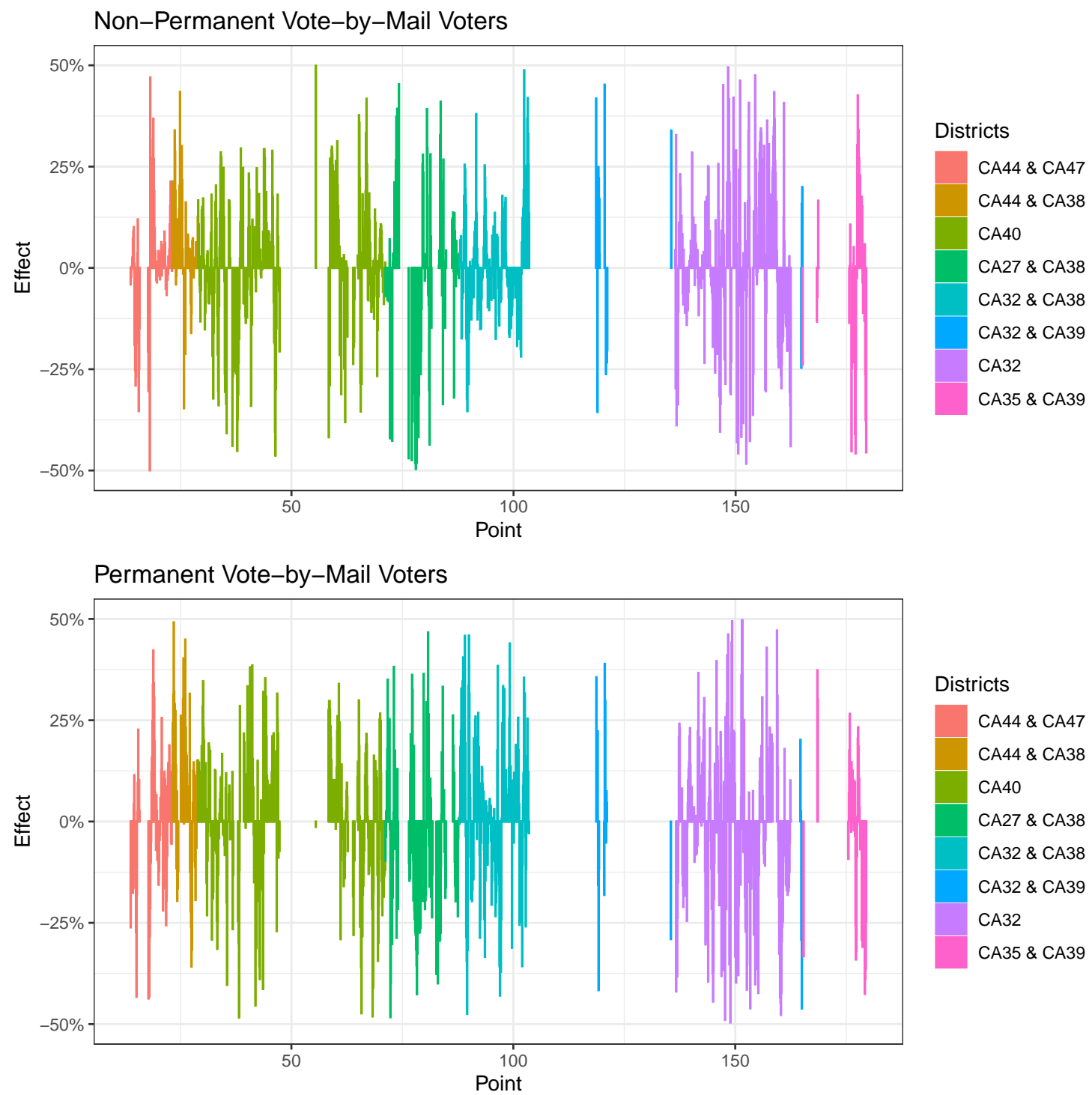

Note: The figure displays the estimates at equidistant points that are 100 meters apart along the boundary using the method proposed in Keele and Titiunik (2015). Points at which there are fewer than 100 non-permanent absentee voters or 100 permanent absentee voters on either side of the boundary are dropped. A small number of points at which the estimates are above $50 \%$ or below $-50 \%$ are also dropped. 


\section{Supplementary Materials Bibliogaphy}

Alvarez, R Michael, Thad E Hall and Brian F Roberts. 2007. "Military Voting and the Law: Procedural and Technological Solutions to the Ballot Transit Problem." Fordham Urb. LJ 34:935.

Barber, Michael and John B Holbein. 2020. "The Participatory and Partisan Impacts of Mandatory Vote-by-Mail.” Science Advances 6(35): eabc7685.

Bonica, Adam, Jacob M. Grumbach, Charlotte Hill and Hakeem Jefferson. 2021. "All-Mail Voting in Colorado Increases Turnout and Reduces Turnout Inequality." Electoral Studies 72: 102363.

Gerber, Alan S, Gregory A Huber, Seth J Hill. 2013. "Identifying the Effects of All-Mail Elections on Turnout: Staggered Reform in the Evergreen State." Political Science Research and Methods 1(1): 91-116.

Gronke, Paul, Eva Galanes-Rosenbaum, Peter A Miller and Daniel Toffey. 2009. “Convenience Voting.” Annu. Rev. Polit.Sci. 11:437-455.

Gronke, Paul and Peter Miller. 2012. "Voting by Mail and Turnout in Oregon: Revisting Southwell and Burchett.” American Politics Research 40(6); 976-997.

Kamarck, Elaine, Yousef Ibreak, Amanda Powers and Chris Stewart. 2020. "Voting by Mail in a Pandemic: A State-by-State Scorecard." Washington, D.C.: The Brookings Institution.

Keele, Luke J and Rocio Titiunik. 2015. "Geographic Boundaries as Regression Discontinuities.” Political Analysis 23(1): 127-155.

Keele, Luke and Rocio Titiunik. 2015. "Geographic Natural Experiments with Interference: The Effect of All-Mail Voting on Turnout in Colorado." CESifo Economic Studies 64(2): 127-149.

McGhee, Eric, Mindy Romero, Laura Daly and Thad Kousser. 2020. "How Did the Voter's Choice Act Affect Turnout in 2018?" California Journal of Politics and Policy 20(1).

Southwell, Priscilla and Justin Burchett. 2000. "Does Changing the Rules Change the Players? The Effect of All-Mail Elections on the Composition of the Electorate." Social Science Quarterly 81(3) 837-845. 
Thompson, Daniel M, Jennifer A Wu, Jesse Yoder and Andrew B Hall. 2020. "Universal Vote-by-Mail Has No Impact on Partisan Turnout or Vote Share." Proceedings of the National Academy of Sciences 117(25): 14052-14056. 